\title{
PREVALENCE OF MUSCULOSKELETAL DISORDERS AND RELATED OCCUPATIONAL CAUSATIVE FACTORS AMONG ELECTRICITY LINEMEN: A NARRATIVE REVIEW
}

\section{VINOTHINI PADMANATHAN ${ }^{1}$, LEONARD JOSEPH ${ }^{1}$, BAHARUDIN OMAR $^{2}$, and ROSLIZAWATI NAWAWI ${ }^{1}$}

\author{
National University of Malaysia, Kuala Lumpur, Malaysia \\ ${ }^{1}$ Faculty of Health Sciences, School of Rehabilitation Sciences, Physiotherapy Program \\ ${ }^{2}$ Faculty of Health Sciences, Department of Biomedical Sciences
}

\begin{abstract}
Occupational tasks of linemen are highly associated with the development of work related musculoskeletal disorders (WRMDs). Although linemen are prone to develop WRMDs, there is paucity of information on the prevalence of WRMDs and related occupational causative factors. Therefore, the present review was conducted to report on the prevalence of WRMDs and to outline causative risk factors within occupational tasks in the lineman profession. Literature search was conducted in various databases such as Scopus, PubMed and ScienceDirect for articles published between 1996-2013. The articles were analyzed, selected and retrieved based on predetermined objectives, inclusion criteria and Medical Subject Headings (MeSH). In the review process only articles published in English were considered. The review identified moderate to high prevalence of WRMDs among the linemen population. Back and shoulder regions were highly affected compared to the other body regions. The review also reported occupational tasks such as bar installation, insulator fixation and manual handling of tools as high risk tasks that lead to the development of WRMDs. In addition, occupational tools such as ladders, manual cutters and manual presses were also identified as a potential ergonomic hazard. In conclusion, the current review identified that WRMDs are common in the back and shoulder regions among linemen. Also, a number of occupational risk factors were identified to be associated with WRMDs among the linemen. Hence, future research on prevention and intervention studies concerning lineman profession population in order to develop a good job practice are recommended. Int J Occup Med Environ Health 2016;29(5):725-734
\end{abstract}

Key words:

Linemen, Work related musculoskeletal disorders, WRMDs, Job risk factors, Occupational health, Ergonomics

\section{INTRODUCTION}

Linemen, or otherwise known as power-line workers, are people who work with electricity in different phases such as troubleshooting, monitoring and repairing of the overhead transmission lines [1]. Working environment of linemen is reported to be hazardous as the nature of the occupation in question involves electricity, which may lead to electrocution and loss of life during working hours [1]. Apart from the electrocution hazard, work related musculoskeletal disorders (WRMDs) among linemen have been a growing concern in recent years due to the physically demanding job tasks [2,3]. The physically strenuous job may predispose

Received: April 11, 2015. Accepted: October 29, 2015.

Corresponding author: L. Joseph, National University of Malaysia, Faculty of Health Sciences, School of Rehabilitation Sciences, Physiotherapy Program, Level 5, Bangunan Yayasan Selangor, Jalan Raja Abdul Aziz, 53100 Kuala Lumpur, Malaysia (e-mail: leonardjoseph85@gmail.com). 
lineman to different types of risk factors reported to cause work related musculoskeletal disorders [4].

Work related musculoskeletal disorders occur due to the presence of physical risk factors in the working environment and job tasks [5]. The National Institute of Occupational Safety and Health (NIOSH) has demonstrated strong evidence on the association of physical risk factors and job tasks with the development of work related musculoskeletal disorders [5]. Studies have indicated a wide variety of physical risk factors such as: static posture, awkward posture, force, vibration and temperature to be associated with musculoskeletal pain among linemen [6,7]. Despite that, there is still lack of evidence on the development of WRMDs among the population of linemen.

Research has recognized that WRMDs in linemen contributes significantly to the sick-leave frequency and reduced productivity [8]. A report by the Electric Power Research Institute (EPRI) has underlined that the lineman profession has the highest percentage (17.7\%) of medical claim costs when compared to other types of occupations related to electricity [8]. A total of 478605 dollars with an average of 517 dollars per lineman was spent as compensation costs alone for a variety of work related musculoskeletal disorders [8]. In addition, physical injuries, such as: strain and sprain, comprised approximately $41.6 \%$ of total cost claim injuries [8]. Nevertheless, the pattern of WRMDs in different body regions among the linemen has not been studied extensively. Thus, limitations and challenges arise for tailoring a healthcare intervention program for prevention and management of WRMDs in the lineman population.

The magnitude of health concerns and reported health problems in the lineman profession requires an in depth review on the prevalence of a WRMDs. Such information is necessary for healthcare policy makers and healthcare professionals to manage WRMDs among the lineman population. In addition, risk factors related to occupational tasks of linemen are of equal importance - in terms of identification of specific tasks that may contribute to the WRMDs. Therefore, the aim of the current review is to address two important questions:

1. What are the patterns of work related musculoskeletal disorders that are prevalent among the linemen population?

2. What are occupational tasks that pose a risk of developing WRMDs among the linemen community?

Hence, a review was conducted between 1996-2013 to report on the prevalence of work related musculoskeletal disorders and related occupational risk factors present in the lineman profession. In the future, information from this review will be beneficial for developing a good job practice and awareness resulting in a healthier and safer working linemen community.

\section{MATERIAL AND METHODS}

\section{Search strategies}

Literature search of articles published from 1996-2013 in ScienceDirect, PubMed and Scopus was conducted. The following Medical Subject Headings (MeSH) were used in the search strategy:

- "linemen" or "lineman" or "line worker" or "power line worker" or "pole worker" or "overhead electrical worker,"

- "musculoskeletal disorders" or "MSDs" or "work related musculoskeletal disorders" or "work related musculoskeletal injuries,"

- "ergonomic" or "hazard" or "risk factors" or "job task analysis,"

- "electricity."

The search strategy attempted to retrieve all relevant studies in a conventional review manner.

\section{Eligibility criteria}

The articles were included for evaluation if they were relevant to the aims that were to be addressed. All the articles were selected according to the following inclusion criteria: 
- includes a study population of linemen/lineman/line workers or power line workers,

- includes measurement of the incidence or prevalence rate of musculoskeletal disorders among this population,

- provides information on methodological issues on the measurement of job tasks analysis associated with the development of musculoskeletal disorders among linemen,

- includes data on measurement of predictive risk factors of WMSDs due to job tasks analysis.

No restrictions concerned age, gender, race or socio-economic status of linemen. For the purpose of this review, only those articles (case control studies, randomized controlled trials, observational case reports, cohort and cross sectional studies) that were published in English were considered for the analysis. Letters to the editor, books and conference proceedings were not considered. The manuscripts that met the inclusion criteria were retrieved, analyzed and interpreted and those that did not meet the above stated criteria were excluded from the analysis.

\section{Data extraction}

Two reviewers reviewed each article independently based on the inclusion criteria. The review team assessed articles on the work related musculoskeletal disorders among the lineman population in terms of different aspects, such as: job tasks analysis and ergonomic hazard analysis. In addition, the articles on ergonomic risk factors and ergonomic interventions aiming at reduction of the occurrence of work related musculoskeletal disorders were also included in the analysis. After reaching an agreement by the review team over the inclusion criteria on the identified articles, full papers were obtained for the review. Any disagreement between the reviewers regarding the articles selection was resolved during a consensus meeting. If agreement could not be achieved during the meeting, a third reviewer was asked to provide a necessary assistance.

\section{RESULTS}

\section{Literature search}

Based on the literature search, a total of 1340 titles were identified. A number of titles were found to be duplicated in the database search. A total number of 11 manuscripts was identified to be included in this review after examining the abstracts and excluding the duplicates (Figure 1). The papers were primarily excluded on the basis that the study did not measure the prevalence or possible causative risk factors of WRMDs among linemen working in the electricity department.

\section{Pattern of various WRMDs among linemen}

Musculoskeletal disorders (MSD) were found in more than $50 \%$ of the total of experienced linemen in the USA, with majority of them suffering from more than one type of accumulative musculoskeletal injury [4]. In a similar retrospective study conducted in the USA, a high risk of back strain has been found among linemen who required time off from the office after the injury [9]. Meanwhile, a study conducted in China has reported a high prevalence of low back (63\%) and shoulder (43\%) musculoskeletal symptoms among linemen [2]. Furthermore, a surveillance report from electric utility companies has described a high incidence rate

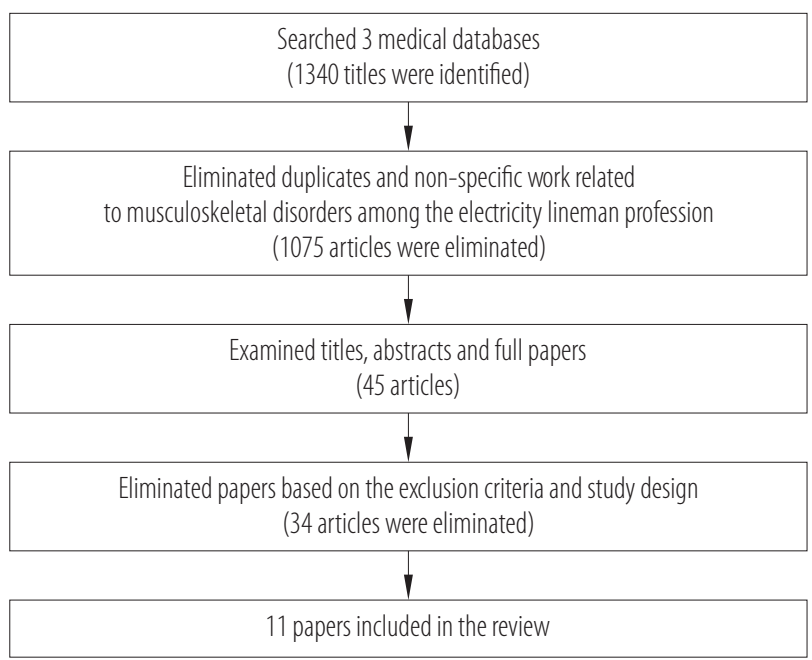

Fig. 1. Selection process of articles for the review 
(13.3 per 10000 employees) of neck injuries among electric utility workers who are basically linemen workers [10]. In addition, a surveillance data from California, USA has reported a high incidence rate of WRMDs due to the overexertion injuries among electricity linemen [11].

\section{Overview of job tasks analysis}

\section{and physical risk factors associated with WMSDs}

A functional job tasks analysis was conducted among various occupations to identify presence of physical risk factors such as: awkward posture, vibration, force and temperature in the working environment $[12,13]$. A number of functional tasks carried out by linemen were identified through the job tasks analysis and presented in Table 1. Working on a pole, insulator fixation, bar installation and changing the transformers were some examples of job tasks performed by linemen $[2,7,14,15]$. However, a variation of job tasks was identified between each paper. Several physical risk factors that increased the risk of development of work related musculoskeletal disorders were identified and presented in Table 2. There is evidence that bar installation and insulator fixation lead to high force exertion. It happens so due to the static neck extension and increased twisting and bending of the lumbar region and limb elevation above the shoulder [2,7,14,15].

A number of tools and equipment used by linemen that increased the risk of WRMDs were also recognized and presented in Table 3. Ladder handling was identified as a risk factor for the overexertion injuries among line workers [2,14]. The specific risk factors for the occurrence of WRMDs were associated with frequent ladder handling and the over-weight of ladders (> $23 \mathrm{~kg}$ ), which was over the limit that has been recommended by the literature [2,14]. Subsequently, wearing a safety belt to strap the linemen to a pole or a ladder was also identified as a risk factor for the development of spinal symptoms such as: lordosis and disc protrusion [2,15]. The use of manual presses and manual cutters during cable-cutting task was also identified as hazardous due to an increase in the exposure to the risk factors such as: awkward posture, high force and increased repetition [3].

In addition to the above risk factors, the review also identified working in different weather conditions, heavy-lifting activities and working environment with electrical wires as part of predictive risk factors for WRMDs [6]. Moreover, an increased weight of the tools, hammering actions and the increased vibration during travelling were also found to be relevant ergonomic risk factors that needed to be considered for the purpose of prevention of WRMDs among the population of linemen $[2,4,7]$.

\section{DISCUSSION}

The review was conducted with an objective to identify functional tasks that were in fact particular risk factors contributing to the prevalence rates of WRMDs in the lineman profession. The review identified a high prevalence rate of WRMDs in different body regions among the lineman population. Back region and shoulder region were mostly affected in linemen. The pattern of WRMDs identified among linemen was similar to several other occupations that involve high manual handling tasks. Moreover, the pattern of WRMDs on shoulder and back regions that was observed among linemen highlights the need for specific joint screening and exercises program among the population of linemen.

Majority of the studies have reported that the prevalence and incidence rate of WRMDs was purely based on data source surveillance [4,9-11]. There was only one study that has been conducted as an on-field clinical surveillance by using a validated screening questionnaire such as the McGill questionnaire to identify the prevalence and incidence rate of WRMDs among the lineman profession [2]. Therefore, one might argue that credibility of the reported results on the prevalence of WRMDs among linemen is questionable. This is because the previous literature has reported that surveillance based solely on data 


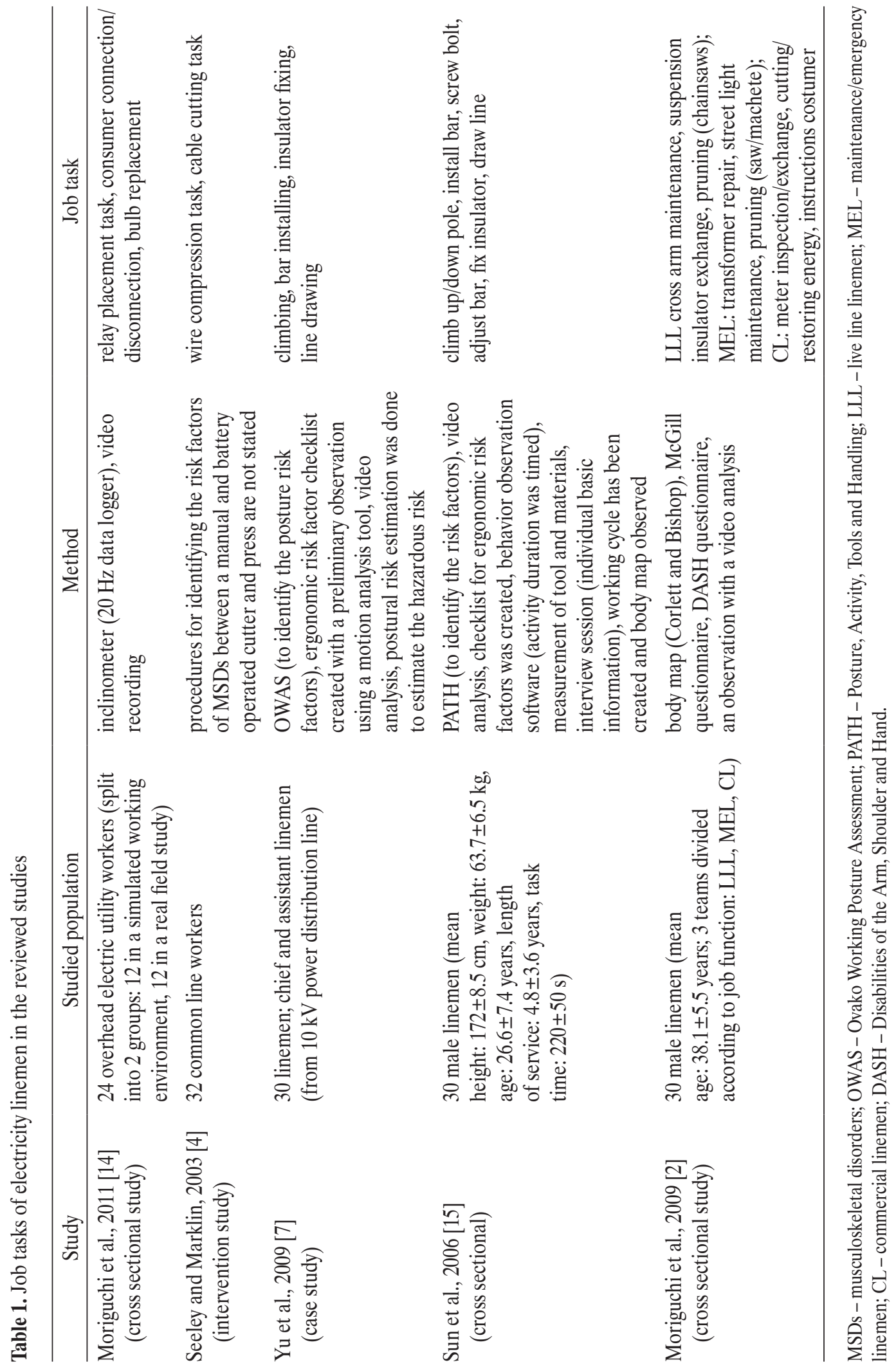




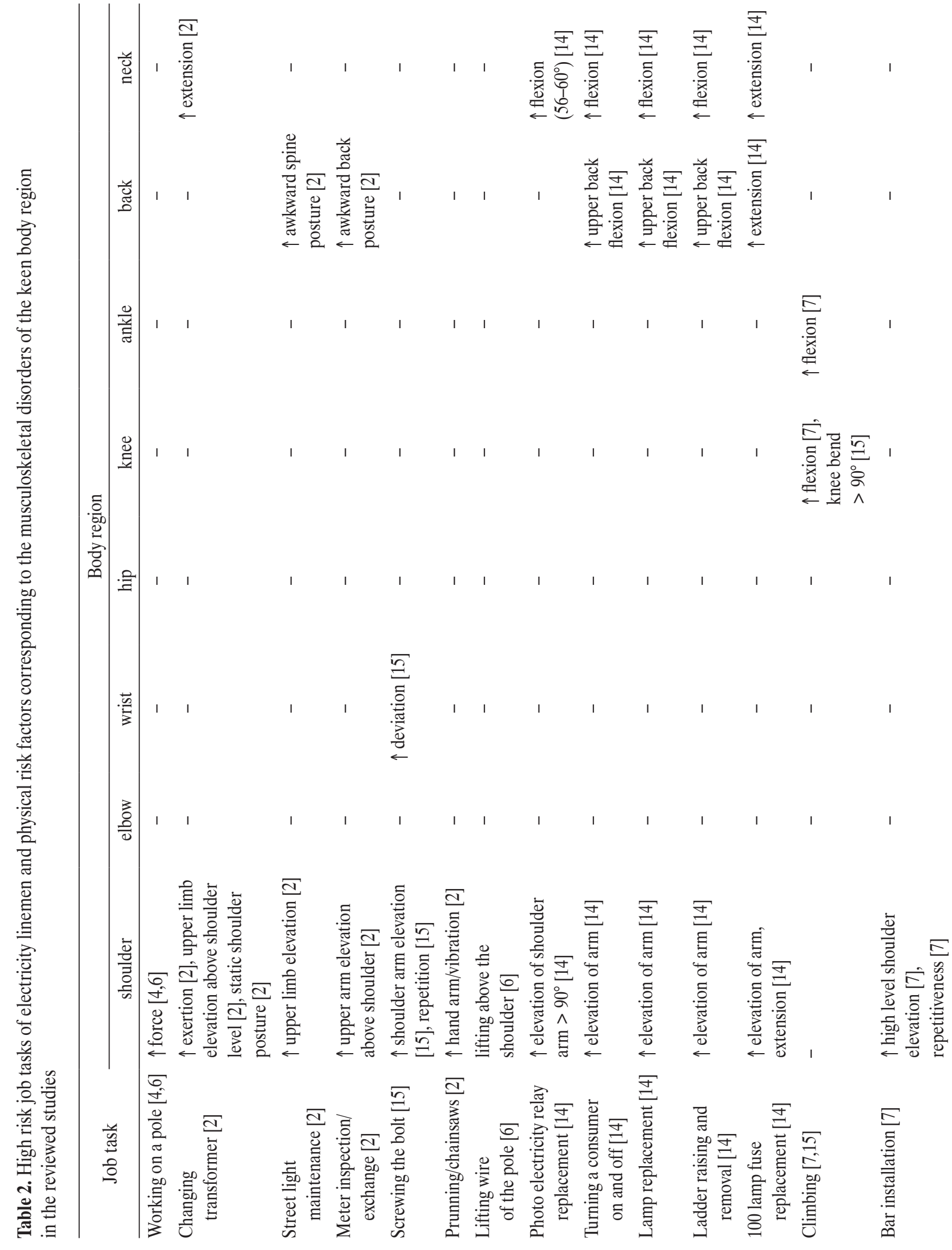




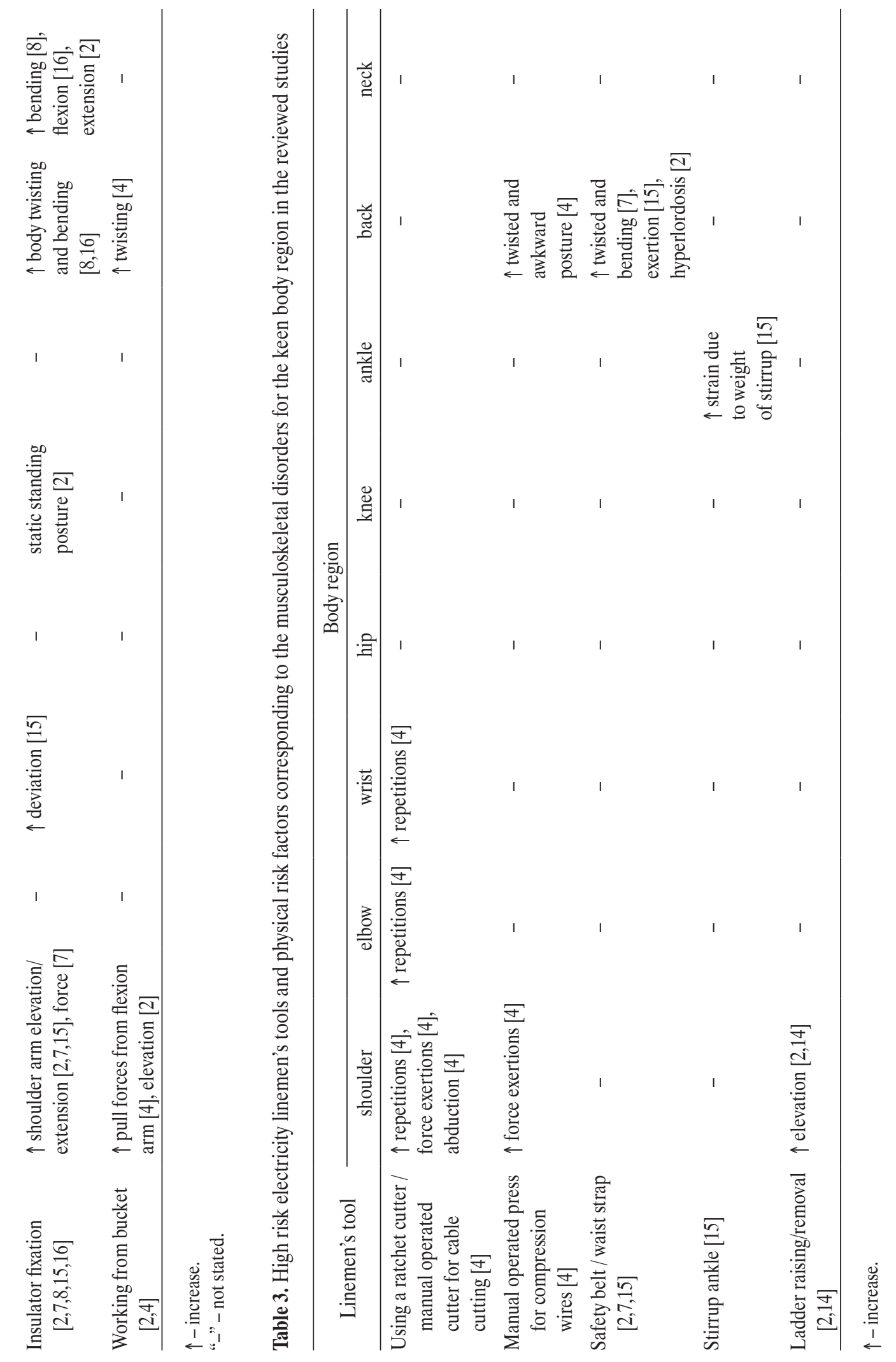


sources such as medical leave records and medical compensations was not sufficient to detect the prevalence rate due to their incompleteness and inaccuracy $[16,17]$.

Hence, the above stated limitations should be addressed in future studies by implementing health surveillance with consistent and validated measurement tools and methods to develop an accurate and precise system to monitor progression of WRMDs among the population of linemen.

In general, only few studies were looked into for the presence of physical risk factors and functional tasks associated with WRMDs within the lineman population [2,7,15]. Although the studies mentioned before identified a variety of job tasks performed by the linemen, surprisingly they have failed to report the presence of physical risk factors in each of the identified working tasks. We acknowledge that the current review identified only a handful of studies focusing on the lineman population. Therefore, it may be argued that very limited research exists on this occupational group all over the world, which may be one of the reasons why other factors, such as: physical risk factors, psychological risk factors and individual risk factors, were not studied extensively.

Nevertheless, in our opinion such factors need to be studied in future studies in order to develop a holistic health approach targeted at the linemen population. Currently, there is insufficient knowledge on the nature of physical risk factors that exist in each type of functional tasks performed by linemen. Therefore, a detailed job tasks analysis is needed for better understanding of the presence of physical risk factors in the working cycle of linemen.

With regard to the identified physical risk factors, two research papers have given a number of suggestions and recommendations to improve and prevent musculoskeletal disorders among the lineman profession [7,15]. Redesigning the linemen platform and safety waist strap, job task redesigning, ergonomic training and implementation of exercise program were recommended as part of prevention strategies [7,15]. However, although the suggestions were based on good ergonomic principles nothing in the literature was found to support such preventive interventions. Hence, further research is also needed to show effectiveness of such interventions in inhibiting development of work related musculoskeletal disorders among the population of linemen.

In a shift of focus from physical hazards, there has been a growing evidence on the association between WRMDs and other multifactorial risk factors such as psychosocial and individual risk factors $[18,19]$. A previous systemic review has shown that the psychosocial and individual risk factors, such as: stress and physical fitness level, play a huge role in the development of WRMDs [20-23]. Despite the existence of current data highlighting the increased stress level and diminished physical fitness level along with increasing age in the linemen population, no study looking into the relationship between individual and psychosocial risk factors on the prevalence of WRMDs among linemen population was found [20-23]. Hence, future research is needed to look into the association between these risk factors and musculoskeletal disorders among the linemen population.

\section{CONCLUSIONS}

Overall, the review identified a number of physical risk factors for WRMDs that were related to the lineman job tasks. High prevalence rate of musculoskeletal pain among linemen constitutes a significant concern for the occupational health sector. Hence, more research should be conducted to prevent or reduce musculoskeletal problems among linemen. It could be achieved by considering other causative risk factors, such as: psychosocial and individual risk factors, in order to have better knowledge on the development of WRMDs among the linemen population. In addition, future studies need to focus more on the prevention strategies so as to develop a good job practice. 


\section{ACKNOWLEDGMENTS}

The authors sincerely thank all the post graduate colleagues who supported completion of this review.

\section{REFERENCES}

1. Brun JP. Work activity and subjectivity: A behind-the-scenes look at the work of linemen. Ind Relat. 1999;50(4):811-25, http://dx.doi.org/10.7202/051055ar.

2. Moriguchi CS, Alencar JF, Miranda-Júnior LC, Coury HJCG. Musculoskeletal symptoms among energy distribution network linemen. Rev Bras Fisioter. 2009;13(2):123-9, http:// dx.doi.org/10.1590/S1413-35552009005000015.

3. Albert A, Hallowel MR. Safety risk management for electrical transmission and distribution line construction. Safety Sci. 2013;51(1):118-26, http://dx.doi.org/10.1016/j.ssci. 2012.06.011.

4. Seeley PA, Marklin RW. Business case for implementing two ergonomic interventions at an electric power utility. Appl Ergon. 2003;34(5):429-39, http://dx.doi.org/10.1016/S00036870(03)00063-2.

5. Bernard BP, editor. Musculoskeletal disorders and workplace factors. A critical review of epidemiologic evidence for workrelated musculoskeletal disorders of the neck, upper extremity, and low back. Cincinnati $(\mathrm{OH})$ : National Institute for Occupational Safety and Health (NIOSH); 1997. p. 97-141.

6. Parkhouse W, Gall B. Task frequency as a function of age for the powerline technician trade. Ergonomics. 2004;47(6): 660-70, http://dx.doi.org/10.1080/00140130410001658682.

7. Yu M, Sun L, Du J, Wu F. Ergonomics hazard analysis of linemen's in power line fixing work in China. Int J Occup Saf Ergon. 2009;15(3):309-17, http://dx.doi.org/10.1080/10803548. 2009.11076812 .

8. Occupational health and safety annual report 2002: Injury and illness trends in the electric energy workforce, 1995-2001.

Palo Alto (CA): Electric Power Research Institute, Inc.; 2002. Final report No. 1005425.

9. Kelsh MA, Fordyce TA, Lau EC, Mink PJ, Morimoto LM, $\mathrm{Lu}$ ET, et al. Factors that distinguish serious versus less severe strain and sprain injuries: An analysis of electric utility workers. Am J Ind Med. 2009;52(3):210-20, http://dx.doi. org/10.1002/ajim.20664.

10. Fordyce TA, Morimoto L, Coalson J, Kelsh MA, Mezei G. Neck injuries among electric utility workers, 1995-2007. J Occup Environ Med. 2010;52(4):441-9, http://dx.doi. org/10.1097/JOM.0b013e3181d86214.

11. Kelsh MA, Lu ET, Ramachandran K, Jesser C, Fordyce T, Yager JW. Occupational injury surveillance among electric utility employees. J Occup Environ Med. 2004;46(9):974-84, http://dx.doi.org/10.1097/01.jom.0000137713.12170.f5.

12. Bernard B, Sauter S, Fine L, Petersen M, Hales T. Job task and psychosocial risk factors for work-related musculoskeletal disorders among newspaper employees. Scand J Work Environ Health. 1994;20(6):417-26, http://dx.doi. org/10.5271/sjweh.1379.

13. Smith DR, Leggat PA, Speare R. Musculoskeletal disorders and psychosocial risk factors among veterinarians in Queensland, Australia. Aust Vet J. 2009;87(7):260-5, http:// dx.doi.org/10.1111/j.1751-0813.2009.00435.x.

14. Moriguchi CS, Carnaz L, Alencar JF, Miranda Júnior LC, Granqvist L, Hansson GA, et al. Postures and movements in the most common tasks of power line workers. Ind Health. 2011;49(4):482-91, http://dx.doi.org/10.2486/indhealth.MS1252.

15. Sun L, Yu M, Sun L. Ergonomic exposures and security on musculoskeletal disorders (MSDs) in power line fixing work. Proceedings of the 2006 International Symposium on Safety Science and Technology; 2006 Oct 24-27; Changsha, Hu'nan, China. Prog Saf Sci Technol. 2006;6(Pt A):561-6.

16. Hagberg M. Surveillance for musculoskeletal problems. In: Violante F, Armstrong T, Kilbom A, editors. Occupational ergonomics: Work related musculoskeletal disorders of the upper limb and back. Boca Raton: CRC Press; 2000. p. 112-9.

17. RoquelaureY, Mariel J, Fanello S, Boissiere JC, Chiron H, Dano C, et al. Active epidemiological surveillance of musculoskeletal disorders in a shoe factory. Occup Environ Med. 2002;59(7):452-8, http://dx.doi.org/10.1136/oem.59.7.452. 
18. Da Costa BR, Vieira ER. Risk factors for work-related musculoskeletal disorders: A systematic review of recent longitudinal studies. Am J Ind Med. 2000;53(3):285-323, http:// dx.doi.org/10.1002/ajim.20750.

19. Heliövaara M, Mäkelä M, Knekt P, Impivaara O, Aromaa A. Determinants of sciatica and low-back pain. Spine. 1991;16(6):608-14, http://dx.doi.org/10.1097/00007632-1991 06000-00002.

20. Martinez MC, Fischer FM. Stress at work among electric utility workers. Ind Health. 2009;47(1):55-63, http://dx.doi. org/10.2486/indhealth.47.55.

21. Hoogendoorn WE, van Poppel MN, Bongers PM, Koes BW, Bouter LM. Systemic review of psychosocial factors at work and private life as risk factors for back pain. Spine. 2015; 25(16):2114-25, http://dx.doi.org/10.1097/00007632-2000081 50-00017.

22. Hamberg-van Reenen HH, Ariëns GA, Blatter BM, van Mechelen W, Bongers PM. A systemic review of the relation between physical capacity and future low back and neck/shoulder pain. Pain. 2007;130(1-2):93-107.

23. Gall B, Parkhouse W. Changes in physical capacity as a function of age in heavy manual work. Ergonomics. 2004;47(6):671-87, http://dx.doi.org/10.1080/001401304100 01658691 .

This work is available in Open Access model and licensed under a Creative Commons Attribution-NonCommercial 3.0 Poland License - http://creativecommons.org/ licenses/by-nc/3.0/pl/deed.en. 